\title{
Long current impulses may be required for nerve stimulation in patients with ischemic pain
}

\author{
[De longues impulsions de courant peuvent être nécessaires pour la stimulation \\ nerveuse en présence de douleur ischémique]
}

Jennifer Szerb MD FRCPC, Desiree Persaud MD FRCPC

Purpose: To report on the efficacy of peripheral plexus catheters in the treatment of ischemic pain in spite of nerve stimulation with long current impulses.

Clinical features: Two patients with severe neuropathic ischemic foot pain are described. A 56-yr-old man with diabetes, renal failure, and autonomic neuropathy presented with severe ischemic foot pain. Opioids produced excess sedation and hypotension. A 62-yr-old woman was admitted after femoralpopliteal bypass and developed a reperfusion pain syndrome not relieved with opioids, gabapentin, amitryptiline, and clonidine. In both patients, a sciatic plexus catheter was placed with resolution of pain. Conventional nerve stimulation, which uses a pulse duration of $0.1 \mathrm{msec}$, did not result in muscle contraction. However, by using a nerve stimulator capable of delivering a I.0 msec impulse duration, a muscle twitch or paresthesia endpoint ensued allowing for successful catheter placement.

Conclusion: Peripheral plexus catheters provide a safe alternative to systemic analgesics for pain relief in patients with ischemic foot pain. However, conventional nerve stimulation techniques may not elicit a motor response in patients with underlying neuropathy, and the use of nerve stimulators capable of delivering long current impulses is recommended.

Objectif : Présenter l'efficacité des cathéters de plexus périphérique utilisés dans le traitement de la douleur ischémique malgré la stimulation nerveuse avec de longues impulsions de courant.

Éléments cliniques: Deux patients éprouvaient d'intenses douleurs neuropathiques ischémiques au pied. Un homme de 56 ans atteint de diabète, d'insuffisance rénale et de neuropathie du système nerveux autonome a consulté pour des douleurs ischémiques intenses au pied. Les opiö̈des produisaient une sédation excessive et de l'hypotension. Une femme de 62 ans a été admise après un pontage fémoro-poplité et a souffert d'un syndrome de dou- leur de reperfusion non soulagé par les opiö̈des, la gabapentine, l'amitryptiline et la clonidine. Chez les deux patients, un cathéter $a$ été mis en place au niveau du plexus sciatique et la douleur a été soulagée. La stimulation nerveuse traditionnelle, avec une pulsation de $0,1 \mathrm{~ms}$, n'a pas produit de contraction musculaire. Mais une stimulation de I,0 ms ayant comme cible une réaction musculaire ou une paresthésie a permis de confirmer la bonne position du cathéter.

Conclusion: Les cathéters du plexus périphérique sont une solution sécuritaire de remplacement aux analgésiques à action générale contre la douleur chez des patients qui ont des douleurs ischémiques au pied. Toutefois, la stimulation nerveuse traditionnelle ne peut déclencher de réaction motrice en cas de neuropathie sous-jacente et l'usage des stimulateurs nerveux capables de fournir de longues impulsions de courant est recommandé.

$\mathrm{P}$ ATIENTS with peripheral vascular disease frequently experience severe pain from their ischemic extremities. ${ }^{1}$ The presence of $\mathrm{co}^{-}$ existing diseases such as renal failure, diabetes, and chronic obstructive lung disease, makes these patients particularly vulnerable to the side effects of opioids. ${ }^{2,3}$ Neuraxial techniques might be contraindicated when patients are on anticoagulants or platelet inhibitors, ${ }^{4}$ limiting the options for pain control. We have provided continuous peripheral nerve blockade for several of these patients referred to us by the acute pain service of our hospital. Conventional nerve stimulation can be of limited value in these patients with abnormal nerves. Two cases are described where peripheral continuous nerve blockade was achieved

From the Department of Anesthesiology, University of Ottawa, Ottawa, Ontario, Canada.

Address correspondence to: Dr. Desiree Persaud, Department of Anesthesiology, The Ottawa Hospital, Civic Campus, 1053 Carling

Avenue, Ottawa, Ontario KlY 4E9, Canada. Phone: 613-761-4169; Fax: 613-761-5032; E-mail: dpersaud@ottawahospital.on.ca Accepted for publication April 20, 2005

Revision accepted May 31, 2005. 
successfully with modifications to conventional nerve stimulation techniques.

\section{Case report \#1}

A 56-yr-old male complained of severe right foot pain at rest for several weeks. His numerous medical problems consisted of IgA nephritis, requiring hemodialysis, hepatitis B-induced cirrhosis, non-insulin dependent diabetes, coronary artery disease, chronic obstructive lung disease, and severe autonomic neuropathy with chronic hypotension. His systolic blood pressure was in the 60 to $80 \mathrm{mmHg}$ range. He became extremely drowsy and more hypotensive (systolic pressures in the 50s) with sustained release of morphine (MS Contin $10 \mathrm{mg}$ bid) and dilaudid 2 to $4 \mathrm{mg} \mathrm{sc}$ administered every three hours for pain.

A right sciatic nerve block was performed at the level of the popliteal fossa using the posterior approach. Using the Stimuplex HNS 11 nerve stimulator (B Braun, Melsungen, Germany) and a 75 mm, 21 gauge Stimulong Plus catheter set (Pajunk, Geisingen, Germany), a barely perceptible motor response was achieved at a $0.1 \mathrm{msec}$ impulse duration at $2.0 \mathrm{~mA}$. With the impulse duration set to $1.0 \mathrm{msec}$, a slight but more convincing twitch in the gastrocnemius muscle was obtained at $0.5 \mathrm{~mA}$. The stimulating catheter was inserted and there was a motor response of the gastrocnemius muscle as the catheter was threaded $8 \mathrm{~cm}$ cephalad at $1.0 \mathrm{~mA}$ and with a 1.0 msec impulse duration. When $40 \mathrm{~mL}$ of mepivacaine $1.5 \%$ with epinephrine $\left(5 \mu \mathrm{g} \cdot \mathrm{mL}^{-1}\right)$ were injected, the patient had onset of pain relief within five minutes, but with the absence of noxious stimulation became quite drowsy and the systolic blood pressure decreased from 80 to $70 \mathrm{mmHg}$. No treatment was required other than supine positioning. He was observed in the postanesthesia care unit for several hours where no adverse effects were noted. There was daily follow-up for catheter site inspection and adequacy of analgesia. An infusion of ropivacaine $0.2 \%$ at $5 \mathrm{~mL} \cdot \mathrm{hr}^{-1}$ provided effective pain relief for the next 13 days. No signs of infection were observed at the insertion site. Over this time the patient was investigated with an angiogram. Decreasing the local anesthetic infusion rate resulted in the return of foot pain. A right popliteal bypass graft was performed 14 days after catheter placement.

\section{Case report \#2}

A 62-yr-old female was admitted two weeks after a successful right femoral to popliteal graft with a provisional diagnosis of reperfusion pain syndrome. She had experienced pain for months in the right foot and had recently undergone two revascularization proce- dures on the same leg. A neurologist was consulted, and diagnosed that the pain was neuropathic with decreased vibratory sensation in the foot, combined with dysesthesia and allodynia. In addition to sustained release hydromorphone (Hydromorph Contin $12 \mathrm{mg}$ po bid) and hydromorphone $2 \mathrm{mg} s c$ every four hours, the patient required gabapentin $p o$, in graded doses, amitriptyline $25 \mathrm{mg}$ po $\mathrm{qHs}$, and clonidine $0.1 \mathrm{mg}$ po every $12 \mathrm{hr}$. Despite these measures, the patient was agitated and distressed with intractable pain.

A sciatic nerve block was attempted via the prone popliteal fossa approach. The popliteal fossa was grossly edematous and no motor response or paresthesia could be obtained using the Stimuplex Dig RC nerve stimulator (B Braun Medical, Bethlehem, PA, USA) and a current up to $2 \mathrm{~mA}$. This nerve stimulator is only capable of delivering impulse durations of $0.1 \mathrm{msec}$. A catheter technique was abandoned, and the patient was placed supine. The sciatic nerve was sought from the lateral popliteal fossa approach with a $50 \mathrm{~mm}, 22$ gauge Stimuplex needle (B Braun Medical, Bethlehem, PA, USA). No motor response was achieved at $2 \mathrm{~mA}$ and an impulse duration of 0.1 ms. However, the patient experienced a paresthesia (sensation of discomfort shooting to the foot), and this was taken as the endpoint. Ropivacaine $0.5 \%$ with epinephrine $\left(5 \mu \mathrm{g} \cdot \mathrm{mL}^{-1}\right), 40 \mathrm{~mL}$, was injected, and the pain was relieved for nearly $24 \mathrm{hr}$. The patient was monitored in the postanesthesia care unit for one hour before returning to her room.

The next day, when the local anesthetic had worn off, a sciatic nerve block was performed between the ischial tuberosity and greater trochanter. ${ }^{5}$ Using the Stimuplex HNS 11 nerve stimulator (B Braun, Melsungen, Germany) and the $75 \mathrm{~mm}$ Stimulong Plus catheter set (Pajunk, Geisingen, Germany), no motor response could be obtained with even the longest duration impulse of $1.0 \mathrm{msec}$ at $2.0 \mathrm{~mA}$. However, at the $1 \mathrm{msec}$ duration setting, paresthesias occurred with each impulse and the catheter threaded easily. No twitch could be obtained via the catheter. Despite this, a bolus of $20 \mathrm{~mL}$ of ropivacaine $0.5 \%$ with $5 \mu \mathrm{g} \cdot \mathrm{mL}^{-1}$ epinephrine was administered through the catheter, and an infusion of ropivacaine $0.2 \%$ at $5 \mathrm{~mL} \cdot \mathrm{hr}^{-1}$ was started. The patient was comfortable with minimal use of opioids. When the infusion was discontinued $48 \mathrm{hr}$ later, the pain was manageable with non-opioid adjuncts (gabapentin, amitriptyline and clonidine), and the patient was discharged three days later.

\section{Discussion}

These cases illustrate the utility of continuous nerve block techniques in patients with ischemic and neuro- 
pathic pain. In the first case, the patient with multiple co-morbidities could receive excellent pain relief via a popliteal fossa catheter without excess hypotension and drowsiness, while the investigations for his peripheral vascular disease ensued. The drowsiness and hypotension after initial block placement was temporary and required no treatment. He had no recurrence on the ward. In the second patient, the use of a sciatic nerve catheter allowed a pain free window period wherein the adjuvant medications had time to reach therapeutic levels.

These cases also illustrate the technical challenge of finding the nerves, and placing catheters in the presence of ischemia and/or neuropathy. Electrophysiological studies in diabetic neuropathy show a reduction of motor and sensory conduction velocities, as well as decreased motor and sensory amplitudes, indicating a loss of myelinated fibres. ${ }^{6}$ Ischemia, secondary to microvascular abnormalities, is the primary cause of axonal degeneration and segmental demyelination. ${ }^{6,7}$ Patients with ischemic extremities can be expected to have abnormal nerves, which do not respond normally to electrical stimulation.

The A alpha motor fibres require a smaller impulse duration for stimulation than A delta and C fibres. ${ }^{8,9}$ Most "conventional" stimulators only emit pulse durations of $0.1 \mathrm{msec}$. This preferentially stimulates motor fibres. The use of the Stimuplex HNS 11 nerve stimulator (B Braun, Melsungen, Germany) allows the selection of impulse durations from 0.1 to 0.3 and $1.0 \mathrm{msec}$. Although the longer pulse durations have been advocated to stimulate sensory nerves, abnormal motor nerves might require pulse durations longer than $0.1 \mathrm{msec}$. Sites et al. ${ }^{10}$ previously reported the inability to elicit a motor response or paresthesia in two diabetic patients at currents as high as $2.4 \mathrm{~mA}$ using a B Braun Stimuplex nerve stimulator, presumably using pulse durations of $0.1 \mathrm{msec}$. This was despite their ability to view the stimulating needle tip in close proximity to the nerve with the use of an ultrasound probe.

The first case required a pulse duration longer than $0.1 \mathrm{msec}$ to elicit a motor response. In the second case, the patient experienced paresthesias at the $1.0 \mathrm{msec}$ setting. Whilst this may have been secondary to direct needle contact, electrical stimulation of the sensory nerves with the longer impulse duration also may have occurred. In this case, the patient's nerves may have been so badly affected by her underlying vascular disease that no motor stimulation was elicited, despite a current of $2.0 \mathrm{~mA}$ and impulse duration of $1.0 \mathrm{msec}$.

In the first case, we noted that the motor twitches elicited via the stimulator were only small contractions of the gastrocnemius muscle, which may be related to muscle atrophy or necrosis resulting from ischemia. Before placement of the block, the patient should be evaluated both on history and physical examination for the presence of neuropathic symptoms or signs of weakness and muscle atrophy, which may prevent or alter a response to nerve stimulation. The vigorous twitch with nerve stimulation accepted as an endpoint in the average patient may be only a slight muscle flicker in the patient with ischemic pain.

Prior to block placement, the presence or absence of sensory deficits should also be documented. Unfortunately, in both of these cases, the patients were in such severe pain that documentation of diminished sensation before block placement could not be accurately determined.

It is the common practice in our institution to perform all peripheral nerve blocks on monitored patients. In both of the cases described, the block procedure occurred in the postanesthesia care unit with continuous 5-lead electrocardiogram monitoring, NIBP, and pulse oximetry and immediate access to emergency drugs and equipment. For initiation of the block, epinephrine was added to the local anesthetic solutions to aid in the detection of an intravascular injection. In addition, monitoring must continue after the block is placed as patients with chronic pain are sleep deprived, and may have accumulation of opioids. The sudden pain relief may be accompanied by excess sedation and hypotension as occurred in our first case.

Patients with vascular disease often have reduced renal function and polypharmacy, and are at risk for drug accumulation and drug interactions. Continuous nerve blocks should be considered in patients with ischemic limb pain, and are particularly valuable in situations where opioids, neuropathic analgesics and neuraxial blocks are ineffective or contraindicated.

These cases illustrate some of the difficulties that may be encountered in nerve stimulation and catheter placement. Solutions to improving the success of the block are presented. The relationship between current, impulse duration and distance from the nerve in patients with ischemic limbs and/or neuropathies is unclear. As the blocks were successful, the needles must have been in close enough proximity to the nerve to allow threading of the catheters and appropriate deposition of local anesthetic.

Ultrasound of peripheral nerves allows for direct visualization of nerves and distribution of local anesthetic. ${ }^{11}$ Ultrasound technology may help with identification of nerves in patients in whom conventional nerve stimulation is problematic. However, even with 
ultrasound guidance intraneural injection may occur. ${ }^{12}$ Our cases suggest that using a nerve stimulator with the ability to deliver long impulse durations may facilitate block placement in patients with ischemic limb pain with or without the use of ultrasound. Further studies are recommended to correlate motor responses, impulse duration and current required with adequacy of block in patients with abnormal nerves.

\section{References}

1 Sumikawa K, Sakai T, Ono T. Peripheral vascular pain (Japanese). Nippon Rinsho 2001; 59: 1733-7.

2 Davis MP, Srivastava M. Demographics, assessment and management of pain in the elderly. Drugs Aging 2003; 20: 23-57.

3 Davison SN. Pain in hemodialysis patients: prevalence, cause, severity, and management. Am J Kidney Dis 2003; 42: 1239-47.

4 Horlocker TT, Wedel DJ, Benzon H, et al. Regional anesthesia in the anticoagulated patient: defining the risks. Reg Anesth Pain Med 2003; 28: 172-97.

5 Raj PP, Parks RI, Watson TD, Jenkins MT. A new single-position supine approach to sciatic-femoral nerve block. Anesth Analg 1975; 54: 489-93.

6 Krarup C. An update on electrophysiological studies in neuropathy. Curr Opin Neurol 2003; 16: 603-12.

7 Dyck PJ, Norell JE, Dyck PJ. Microvasculitis and ischemia in diabetic lumbosacral radiculoplexus neuropathy. Neurology 1999; 53: 2113-21.

8 Pither CE, Raj PP, Ford DJ. The use of peripheral nerve stimulators for regional anesthesia. A review of experimental characteristics, technique, and clinical applications. Reg Anesth 1985; 10: 49-58.

9 De Andres J, Sala-Blanch X. Peripheral nerve stimulation in the practice of brachial plexus anesthesia: a review. Reg Anesth Pain Med 2001; 26: 478-83.

10 Sites BD, Gallagher J, Sparks M. Ultrasound-guided popliteal block demonstrates an atypical motor response to nerve stimulation in 2 patients with diabetes mellitus. Reg Anesth Pain Med 2003; 28: 479-82.

11 Marhofer P, Greher M, Kapral S. Ultrasound guidance in regional anaesthesia. Br J Anaesth 2005; 94: 7-17.

12 Schafhalter-Zoppoth I, Zeitz ID, Gray AT. Inadvertent femoral nerve impalement and intaneural injection visualized by ultrasound (Letter). Anesth Analg 2004; 99: 627-8. 